\title{
Ultrasound guided steroid injection of subacromial bursa: morphologic and clinical effects on patients with supraspinatus tendon calcifications
}

\author{
Nurten ANDAC BALTACIOGLU ${ }^{1}$ (D), Canan SANAL TOPRAK ${ }^{2}$ (D), Efe SOYDEMIR ${ }^{3} \mathbb{0}$, Mehmet Mithat DOKUR ${ }^{4}$ \\ ${ }^{1}$ Department of Radiology, VKV Amerikan Hospital, Istanbul, Turkey. \\ ${ }^{2}$ Department of Physical Therapy and Rehabilitation, Marmara University Pendik Education and Research Hospital, Istanbul, Turkey. \\ ${ }^{3}$ Department of Radiology, Marmara University Pendik Education and Research Hospital, Istanbul, Turkey \\ ${ }^{4}$ Department of Orthopedics and Traumatology, VKV Amerikan Hospital, Istanbul, Turkey.
}

Corresponding Author: Canan SANAL TOPRAK

E-mail: canansanal@hotmail.com

Submitted: 17.01.2020 Accepted: 30.03.2021

\begin{abstract}
Objective: Subacromial injection (SAI), due to its ease of application and increased patient tolerability, is one of the preferred invasive therapies. In this study, we aimed to evaluate effectiveness of ultrasound-guided SAI in patients with supraspinatus calcific tendinitis by assessment of roentgenograms and clinical appraisal.

Patients and Methods: Thirty-five patients with supraspinatus tendon calcifications as revealed by the roentgenography underwent ultrasound-guided SAI. Pre-treatment the Disabilities of the Arm, Shoulder and Hand questionnaire (QuickDASH) scores and Gartner's Classification of calcific tendinitis were obtained. Clinical follow-up was scheduled at 1st, 3rd and 6th months posttreatment along with a single roentgenogram planned at 6 th month.

Results: A total of 53 SAIs were performed on 36 shoulders, 21 female and 14 male patients. Mean size of calcifications were 12.3 and $7.1 \mathrm{~mm}$, pre-treatment and at 6th month, respectively. Pre and post-injection calcification mean sizes in the group with clinical improvement were 13.6 and $5.7 \mathrm{~mm}$; whereas, in group without diminished symptoms, they were 11.8 and $9.4 \mathrm{~mm}$ demonstrating a statistically significant intergroup difference $(\mathrm{p}<0.05)$. Pre-injection QuickDASH mean score was 52.2; this showed improvement at 1st, 3rd and 6th months post-treatment; 20.7, 22.2 and 19.5, respectively.

Conclusion: Subacromial injection is a well-tolerated, easily applicable, safe and effective treatment for pain alleviation in supraspinatus calcific tendinitis.

Keywords: Calcific tendinitis, Shoulder joint, Subacromial bursa, Sonography guided injection, Steroid injection
\end{abstract}

\section{INTRODUCTION}

Calcific tendinitis occurs due to accumulation of calcium hydroxyappatite crystals in tendons close to insertion points. It is most commonly observed in shoulder and hip joints and is a major cause of joint pain. It has been reported to be the culprit in about 7 to $50 \%$ of shoulder artralgia cases $[1,2]$. Approximately, $20 \%$ of patients with rotator cuff calcific tendinits are asymptomatic despite tendon calcifications [3]. Condition progresses through 3 phases initially from formative (precalcific) phase to resting (calcific) phase, and finally to resorptive (postcalcific) phase with gradually worsening symptoms. Most common symptoms are pain, typically in deltoid region, and decreased range of motion especially worsening after exertion or during night. Most painful period is when fragmentation of calcification develops and fragments migrate into adjacent bursae causing bursitis [1] .

Noninvasive palliation through physical therapy and use of nonstereoidal anti-inflammatory drugs are valid treatment options for this usually self-limiting condition. First-line treatment is deemed unsuccessful if clinical improvement cannot be achieved despite minimum total of 3 months of treatment within a 6 months period [4]. In cases where pain could not be alleviated leading to a lesser quality of life, more invasive treatment options should be considered including minimally invasive surgery, extracorporeal shockwave lithotropsy (ESWL), ultrasound

How to cite this article: Andac Baltacioglu N, Sanal Toprak C, Soydemir E, Dokur MM. Ultrasound guided steroid injection of subacromial bursa: morphologic and clinical effects on patients with supraspinatus tendon calcifications. Marmara Med J 2021; 34(2):152-156. doi: 10.5472/marumj.942790 
or fluoroscopy guided needling and lavage (barbotage) and isolated subacromial injection (SAI) $[5,6]$. Among these treatment methods, although there is no consensus which one should be prefered for these patients, SAI is preferred frequently because it can easily be performed and it is also well tolerated by patients [7], but effect of SAI on tendinic calcification levels and clinical outcomes has been controversial. In this study, we aimed to evaluate effectiveness of ultrasound-guided SAI in patients with supraspinatus calcific tendinitis by assessment of the roentgenograms and clinical appraisal.

\section{PATIENTS and METHODS}

This study was approved by the Marmara University School of Medicine ethics committee (approval number: 09.2020.703) and was performed in accordance with the ethical standards as laid down in the 1964 Declaration of Helsinki and its later amndments or comparable ethical standards.

A total of 208 patients who referred to interventional radiology due to chronic shoulder pain between 2017 and 2019, who did not respond to conservative treatment and received ultrasoundguided SAI treatment were reviewed, retrospectively. Among them 35 patients with supraspinatus tendon calcification detected on roentgenographs were included in the study. Case files of 35 patients pertaining to procedure reports, shoulder antero-posterior (AP) roentgenograms, clinical and radiologic outcomes were assessed. The Disabilities of the Arm, Shoulder and Hand Score (QuickDASH) questionnaire was completed by the patients prior to treatment [8]. Gartner's classification was used for the evaluation of tendon calcifications [9]. Number of calcifications and affected tendons, and calcification dimensions were also recorded. In cases with multiple calcifications in the supraspinatus tendon, statistical evaluation of effect of SAI on calcifications was based on interval measurements of the largest calcification prior to intervention. A 4-point Likert scale (completely reduced, significantly reduced, unchanged and worsened) was used for patients to assess their perceptions of pain. While patients with completely and significantly reduced pain were classified as clinically improved, the others were identified as clinically non-improved.

The QuickDASH is a 11-item questionnaire that evaluates symptoms as well as the ability to perform certain activities in patients with any musculoskeletal disorders of the upper limb. It is a 5 point Likert scale ( 1 being no difficulty, 5 being unable). It has also two optional 4-item additional modules: sport/music and work modules. The completed responses are summed and averaged. This value is then transformed to a score out of 100 by subtracting one and multiplying by 25 . Higher scores indicate a greater level of disability and severity [8] .

Gartner's classification is a radiological classification of calcifying tendinitis [9]. It has three types;

Type I: clearly circumscribed, dense calcification, formative

Type II: clearly circumscribed, translucent calcification or dense calcification without a clear outline
Type III: translucent appearance without a clear outline, resorptive

Injections were guided using a Logic E9 sonography device (GE Healthcare, Milwaukee, USA) and a 6-15 MHz linear probe. After appropriate skin preparation and draping, subacromial bursa was entered using a dental needle attached to the tip of a $5 \mathrm{ml}$ disposable syringe and a total of $5 \mathrm{ml}$ sterile mixture of 4 $\mathrm{ml}$ Prilocaine (Citanest) and $1 \mathrm{ml}$ Betamethasone (Diprospan) was injected. Local infiltration anesthesia of the skin and subcutaneous tissues was not performed. Needle entry into tendon calcifications and barbotage were consciously avoided. All patients routinely received oral non-steroidal anti-inflammatory drugs for 3 days post-procedure and use of pain medications was extended up to 15 days when pain did not subside within early post-intervention period. Movement restrictions were not suggested. Patients were called for follow-up at the first, third and sixth months post-injection. The SAI was repeated in patients who did not clinically improve during follow-up. Control roentgenograms were performed at the sixth-month follow-up to record changes in tendon calcifications.

\section{Statistical Analyis}

Data analysis was performed using SPSS Statistics software (Version 23, IBM Corp. Armonk, NY). The normality of the parameters was assessed with Shapiro-Wilk test. Descriptive statistical analyses were done for patient age, gender, treatment response, Gartner classification distribution of calcifications and Quick DASH scores. Dependent samples t-test was used to evaluate effect of SAI on tendon calcification dimensions. Relationship between clinical response to treatment and decrease in tendon calcification dimensions after SAI was assessed by independent sample t-test.

\section{RESULTS}

A total of 35 patients, 21 female and 14 male, with a mean age of $50.6(22-71)$ years had undergone SAI. Mean ages in male and female patient groups were 46.2 (22-68) and 52.7 (29-71) years, respectively. Demographic and clinical data of patients are presented in Table I. Four patients received bilateral shoulder injection; only one of those had tendon calcifications bilaterally. In total, 35 patients and 36 shoulders were included in the study. There were 13 right shoulder and 23 left shoulder involvements. Excluding one patient with bilateral supraspinatus tendon calcifications, 19 patients had involvement of dominant hand side and 15 had calcification of the non-dominant hand side. Average time between onset of shoulder pain and SAI procedure was 5 (range 2-8) months. Technical success was achieved in all patients. There were no early or delayed procedure related complications. A total of 53 SAI were performed on 36 shoulders. Multiple injections were performed on 12 shoulders in different sessions; 7 shoulders received 2 injections while 5 shoulders received 3 injections each due to unremitting pain. During first and third month control visits repeat SAI were performed on a total of 8 and 9 shoulders, respectively. Treatment findings and follow-up results are summarized in Table II. 
Table I. Clinical and demographic data of patients

\begin{tabular}{ll}
\hline Age $_{\text {(years) }}($ mean \pm SD) (min-max) & $50.6 \pm 13.7(22-71)$ \\
Male & $46.2 \pm 11.6(22-68)$ \\
Female & $52.7 \pm 15.4(29-71)$ \\
\hline Gender (Female/Male) & $14 / 21$ \\
\hline Affected side (Right/Left) & $13 / 23$ \\
\hline Affected side ( Dominant/non - dominant) & $20 / 16$ \\
\hline Symptom duration before SAI ${ }_{\text {(months) }}$ (min - max) & $5.2(2-8)$ \\
\hline Gartner's Classification (Type I / type II/ type III) $)$ & $9 / 12 / 15$ \\
\hline Number of SAI & \\
1 injection & 24 Shoulder \\
2 injections & 7 patients \\
3 injections & 5 patients \\
\hline Re-injections & 8 patients \\
1st month & 9 patients \\
3rd month & $52.17 \pm 16.33$ \\
\hline QuickDASH score before SAI (mean \pm SD) & $12.3 \pm 4.9(3.6-24.9)$ \\
\hline $\begin{array}{l}\text { Calcification diameter before SAI }{ }_{(\mathrm{mm})} \text { (mean } \pm \text { SD ) } \\
\text { (min-max) }\end{array}$ & \\
\hline
\end{tabular}

SAI: Subacromial injection, DASH: Disabilities of Arm, Shoulder and Hand

Table II. Treatment and follow-up results

\begin{tabular}{|c|c|c|c|c|}
\hline & $1^{\text {st }}$ month & $3^{\text {rd }}$ month & $6^{\text {th }}$ month & $P$ value \\
\hline Patients (n) & 28 & 32 & 33 & \\
\hline \multicolumn{5}{|l|}{ Pain response } \\
\hline Completely reduced & 18 & 20 & 22 & \\
\hline Significantly reduced & 2 & 3 & 4 & \\
\hline Unchanged & 5 & 8 & 7 & \\
\hline Worsened & 3 & 1 & 0 & \\
\hline \multicolumn{5}{|l|}{ QuickDASH scores } \\
\hline Before SAI $/ 1^{\text {st }}$ month & $49.9 / 20.7$ & $52 / 22.2$ & $51.9 / 19.5$ & $<0.0001$ \\
\hline Before SAI $/ 3^{\text {rd }}$ month & & & & $<0.0001$ \\
\hline Before SAI $/ 6^{\text {th }}$ month & & & & $<0.0001$ \\
\hline \multicolumn{5}{|l|}{ Calcification Diameter $_{(\mathrm{mm})}$} \\
\hline Clincally improved patients & & & $13.6 / 5.7$ & $<0.0001$ \\
\hline Before SAI/ $6^{\text {th }}$ month & & & $11.8 / 9.4$ & 0.24 \\
\hline $\begin{array}{l}\text { Clinically non-improved } \\
\text { patients }\end{array}$ & & & & \\
\hline Before SAI/ $6^{\text {th }}$ month & & & & \\
\hline
\end{tabular}

SAI: Subacromial injection, $p$ :

Calcifications were of Gartner type I in 9, type II in 12 and type III in 15 shoulders. Mean calcification dimension, measured in longest axis, was $12.3 \mathrm{~mm}(3.6-24.9 \mathrm{~mm})$ preintervention. Quick DASH mean score was 52.17 prior to procedure. Patient compliances to follow-up were as follows: 28 shoulders at $1^{\text {st }}$ month; 32 at $3^{\text {rd }}$ month; and 33 at $6^{\text {th }}$ month-visits. Three patients had undergone arthroscopic surgery prior to $6^{\text {th }}$ month visit, hence provided no $6^{\text {th }}$ month control roentgenograms. 18 shoulders were painless and 2 had reduced pain at $1^{\text {st }}$ month control with an average Quick DASH score of 11.02 which was 48 preintervention. At the $3^{\text {rd }}$ month visit 20 shoulders were completely pain-free and 3 were with significantly reduced pain with a mean Quick DASH score of 9.88 which was 49.45 preintervention. At the $6^{\text {th }}$ month visit 22 shoulders were painless and 4 had significantly reduced pain; mean Quick DASH score was 10.05 (preintervention Quick DASH score 48.99).

Arhroscopic surgery was performed in 4 patients due to increased pain after SAI, one of those was after the $6^{\text {th }}$ month-visit. Mean interval between surgery and onset of pain and first SAI were 9.3 and 3.7 months, respectively. Three patients had a single repeat SAI whereas, 1 had two repeat SAI before resorting to surgery.

Calcification types had been altered in 27 of 33 shoulders on the $6^{\text {th }}$ month control roentgenograms. Fourteen Gartner type II calcifications had evolved to type III; whereas type I to type II and type I to type III evolutions were observed in 7 and 6 shoulders, respectively. All shoulders had smaller calcifications in control roentgenograms with a reduced mean longest dimension of 7.1 $\mathrm{mm}$ which was $12.3 \mathrm{~mm}$ prior to SAI. Comparison of interval change of calcification sizes among clinically improved and non-improved patients was statistically significant $(\mathrm{p}<0.05)$. Clinically improved group had preintervention and control calcification dimensions of 13.6 and $5.7 \mathrm{~mm}$ with $58 \%$ postintervention reduction. On the other hand, clinically nonimproved group had only $20 \%$ reduction, from 11.8 to $9.4 \mathrm{~mm}$. All patients with $>50 \%$ reduction in calcification dimensions had either complete or significant remission of shoulder pain.

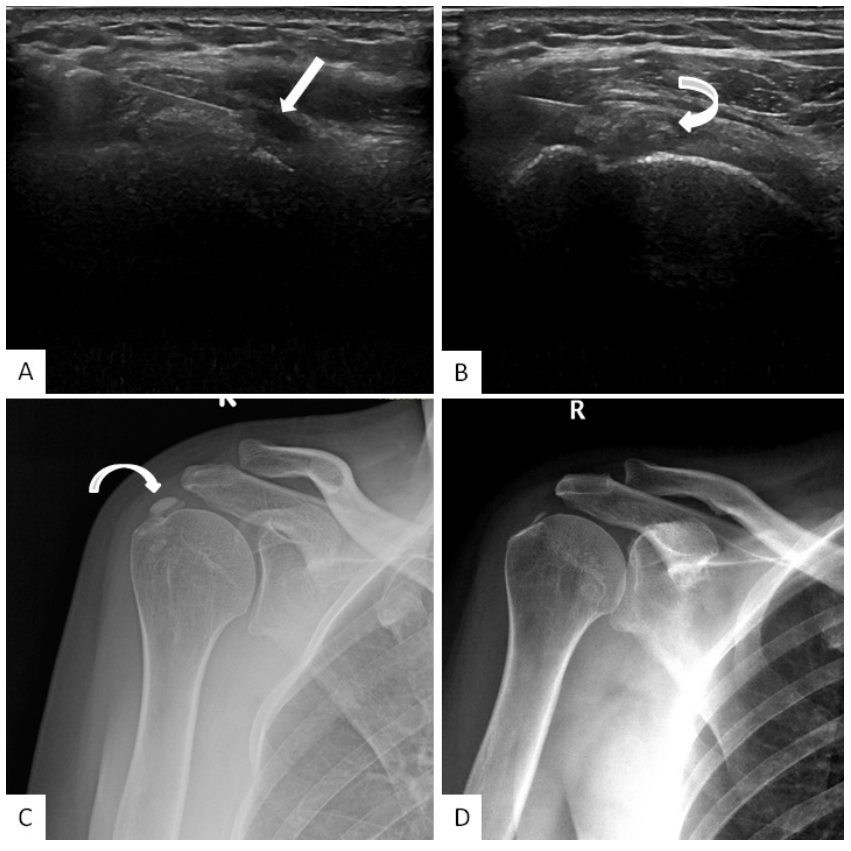

Figure 1. A 53-year-old, female patient. A. Coronal US examination. Tip of needle is seen within subacromial bursa (white arrows). B. Coronal US examination. Calcification is seen at supraspinatus tendon (curved arrow). C. Right shoulder, A-P roentgenogram. Supraspinatu stendon calcification prior to SAI (curved arrow). D. Right shoulder, A-P roentgenogram, sixth month control. Near-total regression of calcification 


\section{DISCUSSION}

The results of this study demonstrated that SAI improves the clinical and radiological findings of patients with calcific tendinitis of supraspinatus. SAI is a widely available treatment method in paitents with rotator cuff tendinitis. Although, clinical outcomes of subacromial steroid injections were found to be favorable for treatment of rotator cuff tendinitis in several studies [10] there is limited data assessing the effectivenes of this treatment in patients with calcific tendinitis.

Sonography guided treatment methods for calcific tendinitis of rotator cuff has become increasingly popular because they are less expensive, more readily accessible and feasible, and can be performed under local anesthesia in an outpatient setting [11]. Two main sonography guided treatment options are barbotage, i.e. needling and aspiration of calcifications, and SAI. SAI generally has the easier application, lower cost and lower complication rate compared to barbotage, and is better tolerated by patients. Barbotage is more invasive and thus more painful and time consuming; it also requires special equipment which in turn necessitates special training and experience. In a randomized controlled study, Witte et al., compared treatment outcomes in two groups with similar baseline Gartner class and Constant shoulder score; one undergoing both barbotage and SAI, and the other treated with SAI alone. Although, barbotage group had better improvement of clinical and radiographic outcomes compared to SAI only group, there was improvement in both treatment groups at 6 months and 1 year follow-up. Total regression of calcifications was observed both barbotage (57\%) and SAI-only (26\%) groups. There were no complications or long-term sequelae post-intervention in both groups. Though, in barbotage group 2 patients developed frozen shoulder which gradually regressed spontaneously [12]. On the other hand, the authors reported the 5-year outcomes of this trial in another study and revealed that no more significant differences were found in the clinical and radiological outcomes between groups. [5] In our study, $72 \%$ of shoulders (26 out of 36 ) had either total or marked regression of pain symptoms by six months postintervention. In a previous study, similar to our results $72 \%$ of patients showed clinically significant improvement with conservative treatments of calcific tendinitis [13]. Varying results have been reported regarding the radiologic changes of calcifications depending on treatment methods. Elimination rates of calcific deposits with barbotage have been shown $72.2 \%$ in a recent study [14]. In patients treated with ESWT, the rate of totally removed calcifications was reported as $86.6 \%$ [15]. With conservative tratments, $62 \%$ of the calcific deposits presented complete resolution (12\%) or decrease (50\%) in the size of calfication [13]. There was no complete resolution in our study however, reduction of calcifation size was present in all patients.

Although, initial radiologic type and size were not found to be related with clinical results in a previous study [13], we found that reduction of calcification size was 58\% in responsive group, whereas it was $20 \%$ in non-responsive group. In a noninferiority study, the authors hypothesised that steroid injections are not necessary after the barbottage and saline solution was non-inferior to steroids. However, non-inferiority of saline could not be proven and the results showed that although steroids have no significant effect on calcification resorption they are beneficial for decreasing pain and disability in the short term when compared to saline [16].

The results of all these studies suggested that good radiologic outcomes may be expected with all conservative treatment methods and SAI may have additional effects on pain and functional improvement in patients with calcific tendinitis of the supraspinatus tendon.

The study has also some limitations. First of all, a control group, treated with other conservative treatment methods could not be included in this study due to its retrospective design. Effectiveness of SAI in calcific tendinitis treatment needs to be verified and compared to other treatment options in larger prospective randomized controlled settings.

In conclusion; SAI treatment is a feasible, safe and well tolerated treatment option in alleviating shoulder pain of calcific tendinitis of the supraspinatus tendon.

\section{Compliance with Ethical Standards}

Ethical approval: This study was approved by the Marmara University School of Medicine Ethics Committee (approval number: 09.2020.703) and was performed in accordance with the ethical standards as laid down in the Declaration of Helsinki and its later amendments or comparable ethical standards.

Financial support: The authors have no relevant financial information to disclose.

Conflict of interest: The authors have no potential conflicts to declare.

Authors' contributions: Conceptualization: $\mathrm{NAB}$ and MD, Data collection: NAB and MD,

Data analysis: NAB, ES and CST, Investigation: NAB, ES, CST and MD, Supervision: NAB and MD, Writing original draft: $\mathrm{NAB}, \mathrm{ES}$ and MD, Writing - Review and editing: NAB and CST

\section{REFERENCES}

[1] Siegal DS, Wu JS, Newman JS, del Cura JL, Hochman MG. Calcific tendinitis: a pictorial review. Can Assoc Radiol J 2009; 60: 263-72. doi: 10.1016/j.carj.2009.06.008

[2] Albert J-D, Meadeb J, Guggenbuhl P, Marin F, et al. High-energy extracorporeal shock-wave therapy for calcifying tendinitis of the rotator cuff: a randomised trial. Bone Joint J British volume 2007; 89: 335-41. doi: 10.1302/0301-620X.89B3.18249

[3] Merolla G, Singh S, Paladini P, Porcellini G. Calcific tendinitis of the rotator cuff: state of the art in diagnosis and treatment. J Orthop Traumatol 2016; 17: 7-14. doi: 10.1007/ s10195.015.0367-6

[4] Ogon P, Südkamp NP, Jaeger M, Izadpanah K, Koestler W, Maier D. Prognostic factors in nonoperative therapy for chronic symptomatic calcific tendinitis of the shoulder. Arthritis Rheum 2009; 60: 2978-84. doi: 10.1002/art.24845 
[5] de Witte PB, Kolk A, Overes F, Nelissen RG, Reijnierse M. Rotator cuff calcific tendinitis: ultrasound-guided needling and lavage versus subacromial corticosteroids: five-year outcomes of a randomized controlled trial. Am J Sports Med 2017; 45: 3305-14. doi:10.1177/036.354.6517721686

[6] Oudelaar BW, Huis R, Schepers-Bok R, Ooms EM, Nelissen RG, Vochteloo AJ. Prognostic factors for the outcome of needle aspiration of calcific deposits for rotator cuff calcific tendinitis. Eur Radiol 2020; 30: 4082-90. doi: 10.1007/ s00330.020.06669-0.

[7] Arirachakaran A, Boonard M, Yamaphai S, Prommahachai A, Kesprayura S, Kongtharvonskul J. Extracorporeal shock wave therapy, ultrasound-guided percutaneous lavage, corticosteroid injection and combined treatment for the treatment of rotator cuff calcific tendinopathy: a network meta-analysis of RCTs. Eur J Orthop Surg Traumatol 2017; 27: 381-90. doi: 10.1007/s00590.016.1839-y

[8] Gummesson C, Ward MM, Atroshi I. The shortened disabilities of the arm, shoulder and hand questionnaire (Quick DASH): validity and reliability based on responses within the fulllength DASH. BMC Musculoskelet Disord 2006; 7: 1-7. doi: 10.1186/1471-2474-7-44 dash

[9] Gärtner J, Simons B. Analysis of calcific deposits in calcifying tendinitis. Clin Orthop Relat Res 1990: 254:111-20.

[10] Arroll B, Goodyear-Smith F. Corticosteroid injections for painful shoulder: a meta-analysis. Br J Gen Pract 2005; 55: 224-8.

[11] Serafini G, Sconfienza LM, Lacelli F, Silvestri E, Aliprandi A, Sardanelli F. Rotator cuff calcific tendonitis: short-term and 10-year outcomes after two-needle US-guided percutaneous treatment-nonrandomized controlled trial. Radiology 2009; 252: 157-64. doi: 10.1148/radiol.252.108.1816

[12] de Witte PB, Selten JW, Navas A, et al. Calcific tendinitis of the rotator cuff: a randomized controlled trial of ultrasound-guided needling and lavage versus subacromial corticosteroids. Am J Sports Med 2013; 41: 1665-73. doi: 10.1177/036.354.6513487066

[13] Cho NS, Lee BG, Rhee YG. Radiologic course of the calcific deposits in calcific tendinitis of the shoulder: does the initial radiologic aspect affect the final results? J Shoulder Elbow Surg 2010; 19: 267-72. doi: 10.1016/j.jse.2009.07.008

[14] Kim Y-S, Lee H-J, Kim Y-V, Kong C-G. Which method is more effective in treatment of calcific tendinitis in the shoulder? Prospective randomized comparison between ultrasoundguided needling and extracorporeal shock wave therapy. J Shoulder Elbow Surg 2014; 23: 1640-6. doi:10.1016/j. jse.2014.06.036

[15] Cacchio A, Paoloni M, Barile A, et al. Effectiveness of radial shock-wave therapy for calcific tendinitis of the shoulder: single-blind, randomized clinical study. Phys Ther 2006; 86: 672-82. doi: $10.1093 / \mathrm{ptj} / 86.5 .672$

[16] Darrieutort-Laffite C, Varin S, Coiffier G, et al. Are corticosteroid injections needed after needling and lavage of calcific tendinitis? Randomised, double-blind, non-inferiority trial. Ann Rheum Dis 2019; 78: 837-43. doi: 10.1136/ annrheumdis-2018-214971 